\title{
Adjunctive vacuum-assisted aspiration thrombectomy in a patient with acute limb ischaemia and peronea arteria magna
}

\author{
Spyros Papadoulas, ${ }^{1}$ Natasa Kouri, ${ }^{2}$ Francesk Mulita $\left({ }^{0},{ }^{3}\right.$ Konstantinos Katsanos ${ }^{4}$
}

'Department of Vascular Surgery, University General Hospital of Patras Holy Mary the Help, University of Patras, Patras, Greece

${ }^{2}$ Department of Vascular Surgery, University General Hospital of Patras Holy Mary the Help, Patra, Greece

${ }^{3}$ Department of General Surgery, University General Hospital of Patras Holy Mary the Help, Patras, Greece

${ }^{4}$ Department of Interventional Radiology, University General Hospital of Patras Holy Mary the Help, Patra, Greece

\section{Correspondence to}

Francesk Mulita;

oknarfmulita@hotmail.com

Accepted 10 August 2021

\section{DESCRIPTION}

A 63-year-old woman presented with acute left foot ischaemia with pain, sensory loss and moderate motor deficit. She was a heavy smoker with arterial hypertension, hyperlipidaemia and a history of left breast cancer 15 years ago. She urgently underwent a standard Fogarty embolectomy through a left groin common femoral artery incision under local anaesthesia. An arterial embolus with minimal amount of fresh thrombus was retrieved. The leg regained partial mobility and sensation, but the forefoot remained cold, pale and painful. Urgent intraoperative digital subtraction angiogram (DSA) is not normally performed in our department due to staff and equipment problems. The patient underwent a DSA in the Interventional Radiology Suite postoperatively where the equipment and experience are highly available. It revealed a dominant peroneal artery that was occluded above the level of malleolus with a completely deserted foot. Beyond this level, no vessel was opacified (figure 1A). Anterior tibial artery was hypoplastic but patent until mid-calf. An image-guided percutaneous vacuum-assisted aspiration thrombectomy with the INDIGO/PENUMBRA catheter was performed (figure 1B). Through the peroneal artery, using a $6 \mathrm{~F}$ catheter, thrombus was retrieved from the plantar vessels down to the midsole, restoring normal vessel patency (figures 2 and 3). Posterior tibial pulses were restored, the foot immediately reperfused and pain was relieved. Holter test was normal and lung adenocarcinoma was later diagnosed. We suppose that the cause of
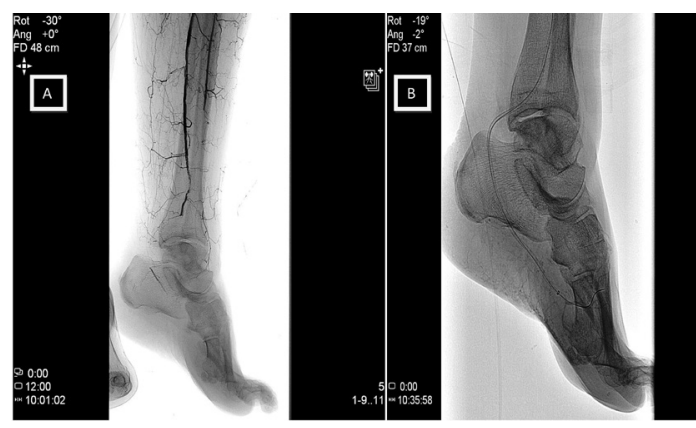

Figure 1 (A) Baseline angiogram shows abrupt cut-off of the anterior tibial and peroneal arteries with missing posterior tibial artery and without any opacification of the foot vessels ('desert foot'). (B) Percutaneous thromboaspiration with use of the INDIGO/PENUMBRA devise across the dominant peroneal artery extending to the distal plantar arch.
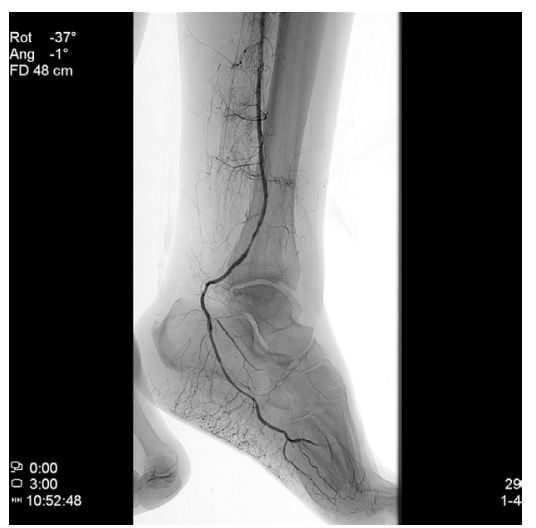

Figure 2 Completion angiogram depicts successful recanalisation of the dominant peroneal with brisk filling up of the foot microvasculature.

ALI was thromboembolism due to hypercoagulability related to lung cancer disease (paraneoplastic syndrome). One month later, her leg was asymptomatic and peroneal colour duplex was normal. Dominant peroneal artery (peronea arteria magna)

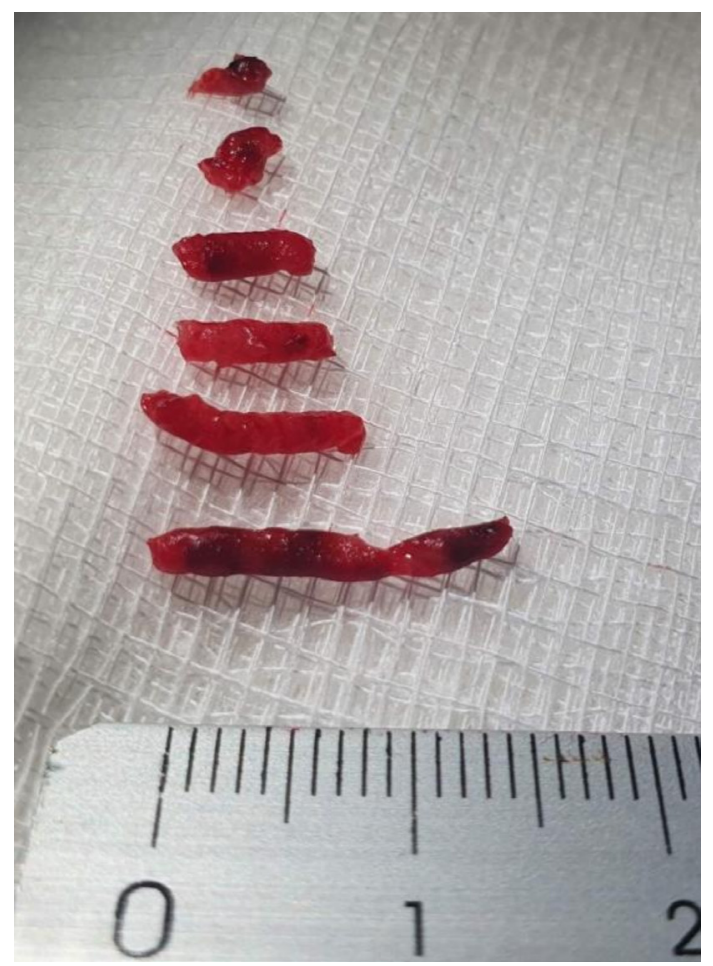

Figure 3 Aspirated thromboemboli after successful foot revascularisation. 
is a rare congenital variation (incidence $<5 \%$ ) where a large dominant peroneal artery may perfuse the calf and foot, while the anterior and posterior tibial arteries are hypoplastic. The Indigo/Penumbra device, developed for acute ischaemic stroke, has also gained popularity in acute limb ischaemia with satisfactory results. ${ }^{1-5}$

\section{Learning points}

- The remaining severe foot ischaemia after a successful surgical Fogarty thromboembolectomy down to the level of malleolus may represent residual obstruction of the plantar arch.

- New percutaneous techniques like INDIGO/PENUMBRA devise have been proved valuable to remove thrombi in the plantar vasculature.

Contributors SP and NK had the idea of the study. SP and FM prepared the manuscript. KK critically revised the manuscript. All authors accepted the final version of the manuscript.
Funding The authors have not declared a specific grant for this research from any funding agency in the public, commercial or not-for-profit sectors.

Competing interests None declared.

Patient consent for publication Obtained.

Provenance and peer review Not commissioned; externally peer reviewed.

ORCID iD

Francesk Mulita http://orcid.org/0000-0001-7198-2628

\section{REFERENCES}

1 de Donato G, Pasqui E, Sponza M, et al. Safety and efficacy of vacuum assisted Thrombo-Aspiration in patients with acute lower limb ischaemia: the Indian trial. Eur J Vasc Endovasc Surg 2021:61:1078-5884(21)00047-2.

2 Lopez R, Yamashita TS, Neisen M, et al. Single-Center experience with indigo aspiration thrombectomy for acute lower limb ischemia. J Vasc Surg 2020;72:226-32.

3 Saxon RR, Benenati JF, Teigen C, et al. Utility of a power Aspiration-Based extraction technique as an initial and secondary approach in the treatment of peripheral arterial thromboembolism: results of the multicenter prism trial. J Vasc Interv Radio 2018;29:92-100.

4 Betz LH, Betz BW. Peronea arteria magna. Pediatr Radiol 2009;39:1016.

5 Björck M, Earnshaw JJ, Acosta S, et al. Editor's Choice - European Society for Vascular Surgery (ESVS) 2020 Clinical Practice Guidelines on the Management of Acute Limb Ischaemia. Eur J Vasc Endovasc Surg 2020;59:173-218.

Copyright 2021 BMJ Publishing Group. All rights reserved. For permission to reuse any of this content visit

https://www.bmj.com/company/products-services/rights-and-licensing/permissions/

BMJ Case Report Fellows may re-use this article for personal use and teaching without any further permission.

Become a Fellow of BMJ Case Reports today and you can:

- Submit as many cases as you like

- Enjoy fast sympathetic peer review and rapid publication of accepted articles

- Access all the published articles

- Re-use any of the published material for personal use and teaching without further permission

\section{Customer Service}

If you have any further queries about your subscription, please contact our customer services team on +44 (0) 2071111105 or via email at support@bmj.com.

Visit casereports.bmj.com for more articles like this and to become a Fellow 